\title{
Highly Selective Electrochemical Determination of Phlorizin Using Square Wave Voltammetry at a Boron-Doped Diamond Electrode
}

\author{
Eda Mehmeti ${ }^{1}$ • Dalibor M. Stanković ${ }^{2,3}$ • Astrid Ortner ${ }^{4} \cdot$ Janez Zavašnik $^{5}$. \\ Kurt Kalcher ${ }^{1}$
}

Received: 22 February 2017 / Accepted: 7 May 2017 /Published online: 30 May 2017

(C) The Author(s) 2017. This article is an open access publication

\begin{abstract}
A boron-doped diamond electrode was used as an electrochemical sensor for the determination of phlorizin (aka phloridzin, phlorrhizin) using square wave voltammetry (SWV). Phlorizin (Phl) exhibited a well-defined oxidation peak at $+0.9 \mathrm{~V}$ (versus $\mathrm{Ag} / \mathrm{AgCl}$ electrode $3 \mathrm{M} \mathrm{KCl}$ ) in solutions with a $\mathrm{pH}$ value of 6.0. Parameters such as $\mathrm{pH}$ value and scan rate were optimized for cyclic voltammetry as well as amplitude and frequency for SWV. The sensor gave excellent response with a wide linear dynamic range for concentrations of phlorizin from 3 to $100 \mu \mathrm{M}$ with a detection limit of $0.23 \mu \mathrm{M}$ and a good repeatability $( \pm 0.9 \%, n=7$ measurements, $c=10 \mu \mathrm{M})$. The effect of interferences by most common compounds was tested, and the method was successfully applied to the determination of the title compound in apple root extracts and urine samples with satisfactory recovery.
\end{abstract}

Electronic supplementary material The online version of this article (doi:10.1007/s12161-017-0935-x) contains supplementary material, which is available to authorized users.

Eda Mehmeti

eda_mehmeti@hotmail.com

$\triangle$ Kurt Kalcher

kurt.kalcher@uni-graz.at

1 Institute of Chemistry-Analytical Chemistry, Karl-Franzens University, Universitätsplatz 1/I, 8010 Graz, Austria

2 The Vinča Institute of Nuclear Sciences, University of Belgrade, POB 522, Belgrade 11001, Serbia

3 Department of Analytical Chemistry, Innovation Center of the Faculty of Chemistry, University of Belgrade, Studentski trg 12-16, Belgrade 11000, Serbia

4 Department of Pharmaceutical Chemistry, Karl-Franzens University, Universitätsplatz 1/II, 8010 Graz, Austria

5 Centre for Electron Microscopy and Microanalysis, Jozef Stefan Institute, Jamova 39, Ljubljana 1000, Slovenia
Keywords Boron-doped diamond electrode · Phlorizin · Voltammetric sensor - Apple root extracts

\section{Introduction}

Phlorizin $(\mathrm{Phl}, \mathrm{pKa}=7.89)$ is a natural product which is found in a number of fruit trees primarily in apple (Malus) species widely distributed in the bark and leaves (de Koninck 1835a, b).

It belongs to the chalcone class of flavonoids (Wang et al. 2013), and it is sometimes also named phloridzin, phlorrhizin, phlorhizin, or phlorizoside. Phl has many biological functions, such as antioxidase activity, regulation of glucose transport, and the ability to induce apoptosis in tumor cells (Chang et al. 2012). Phl reduces renal glucose transport, lowering the amount of glucose in the blood. Phl and its derivatives have found wide usage in food and beverage industry as well as additive in pharmaceuticals and cosmetics (Zhu et al. 2013; $\mathrm{Kim}$ et al. 2014). There are several research articles published related to phlorizin and its derivatives' pharmacological effect (Ostroumova et al. 2013; Shin et al. 2011; Lee et al. 2011). Especially, the effect of phlorizin on glucose uptake and diabetes has been intensively examined and was reviewed. It prevents the uptake of glucose into the brain and decreases its availability (Ehrenkranz et al. 2005).

Up to now, there are several electroanalytical methods reported for the determination of the total antioxidant capacity (Pekec et al. 2013; Rebelo et al. 2013; Tirawattanakoson et al. 2016; Gao et al. 2015; Petkovic et al. 2015) and chromatographic methods using different detectors such as highperformance liquid chromatography (HPLC) in combination with electrospray ionization tandem mass spectrometry (Lijia et al. 2014), with nuclear magnetic resonance and mass spectroscopy (NMR-MS) (Lommen et al. 2000; Tsao et al. 2003), 
with a diode array (Tsao et al. 2003), or a multielectrode coulometric detector (Crespy et al. 2001).

Electrochemical methods have received excessive attention due to their simplicity in instrumentation setup, sensitivity, low cost, and fast response time (Schachl et al. 1997). Nowadays, the use of boron-doped diamond electrode (BDD) is significantly increasing and it is one of the most preferred solid electrode material due to a chemical inertness, very low background currents, low adsorption, and a wide applicable potential window (Svorc et al. 2014; Pecková et al. 2009). The electrode is also environmentally friendly, highly sensitive, long-term stable and it can be used for the determination of different biologically active compounds with significant importance in the field of food, environment, and drug analysis (Stanković and Kalcher 2015; Stanković 2015).

The aim of this work was to investigate the electrochemical behavior of this important biologically active compound with BDD electrode and to develop a simple, fast, and sensitive method for the determination of Phl at low concentrations.

\section{Experimental}

\section{Chemicals}

Boric acid, sodium hydroxide, acetic acid, phosphoric acid, and phlorizin (99\%) were purchased from SigmaAldrich and used as received without any further purification. All other chemicals were of analytical reagent grade. Deionized water with a resistivity of $18 \mathrm{M} \Omega \mathrm{cm}$ (Millipore Milli-Q system) was used for the preparation of all the solutions.

Calibration and working solutions of Phl were prepared from the stock solution by appropriate dilution with BrittonRobinson (BR) buffer as supporting electrolyte. The latter was prepared by mixing of phosphoric acid, acetic acid, and boric acid solutions (each with a concentration of $40 \mathrm{mM}$ ). The $\mathrm{pH}$ of different BR buffers was adjusted using sodium hydroxide of $0.2 \mathrm{M}$.

\section{Apparatus}

Cyclic voltammetric (CV) and square wave voltammetric (SWV) measurements were performed with an Autolab PGSTAT $302 \mathrm{~N}$ potentiostat/galvanostat controlled by corresponding software (Nov. 1.10). The electrochemical cell $(10 \mathrm{~mL})$ consisted of a glass vessel equipped with an $\mathrm{Ag} /$ $\mathrm{AgCl}$ reference electrode (3 $\mathrm{M} \mathrm{KCl}$, Metrohm 6.0733.100), a platinum wire as a auxiliary electrode and the BDD working electrode (embedded in a polyether ether ketone body with an inner diameter of $3 \mathrm{~mm}$, a resistivity of $0.075 \Omega \mathrm{cm}$ and a boron doping level of $1000 \mathrm{mg} / \mathrm{dm}^{3}$ as obtained by Windsor Scientific LTD, UK). The BDD electrode was cleaned with deionized water and gently rubbed with a piece of damp silk cloth until a mirror-like appearance of the surface was attained. If the electrode was new, it was anodically pretreated using a potential of $+2 \mathrm{~V}$ for $180 \mathrm{~s}$ in $1 \mathrm{M} \mathrm{H}_{2} \mathrm{SO}_{4}$ followed by cathodic pretreatment at $-2 \mathrm{~V}$ during $180 \mathrm{~s}$ to renew the hydrogen-terminated surface of the working electrode. The stability of the BDD electrode before and after one or a few series of measurements was controlled with an equimolar mixture of $\mathrm{K}_{4}\left[\mathrm{Fe}(\mathrm{CN})_{6}\right] / \mathrm{K}_{3}\left[\mathrm{Fe}(\mathrm{CN})_{6}\right]$ couple. $\mathrm{pH}$ values were measured using a calibrated $\mathrm{pH}$ meter (Orion, model 1230) with a combined electrode. All potentials given in the text are versus the $\mathrm{Ag} / \mathrm{AgCl}$ reference electrode at room temperature $\left(22 \pm 2{ }^{\circ} \mathrm{C}\right)$.

\section{Procedures}

Cyclic voltammograms were recorded with a scan rate of $0.1 \mathrm{~V} / \mathrm{s}$ in a potential range between 0 and $+1.5 \mathrm{~V}$ (versus $\mathrm{Ag} / \mathrm{AgCl})$ using BR buffer $(10 \mathrm{~mL})$. The standard concentration of $\mathrm{Phl}$ in the measurements solution was $0.1 \mathrm{mM}$.

For quantitative determinations, square wave voltammetry was applied in potential range from 0 to $+1.5 \mathrm{~V}$ with the following optimized parameters: scan rate of $0.05 \mathrm{~V} / \mathrm{s}$, pulse amplitude of $0.01 \mathrm{~V}$, and frequency of $20 \mathrm{~Hz}$.

\section{Interference Studies}

Interferents were investigated in concentrations of $30 \mu \mathrm{M}$ under optimized experimental conditions with SWV. The peak currents of $30 \mu \mathrm{M} \mathrm{Phl}$ were recorded in the absence and in the presence of interferents.

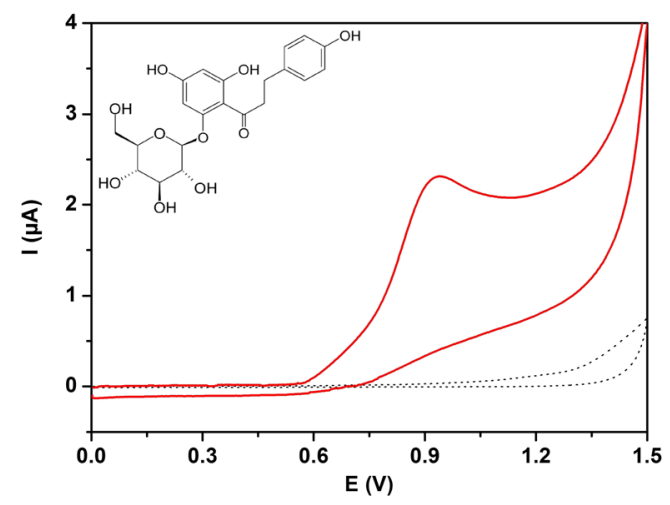

Fig. 1 Cyclic voltammogram of $\mathrm{Phl}$ at a BDD electrode; dotted line blank; full line $0.1 \mathrm{mM} \mathrm{Phl;} \mathrm{supporting} \mathrm{electrolyte,} \mathrm{BR} \mathrm{buffer} \mathrm{(} \mathrm{pH} 6.0$ ); scan rate, $0.1 \mathrm{~V} / \mathrm{s}$ 


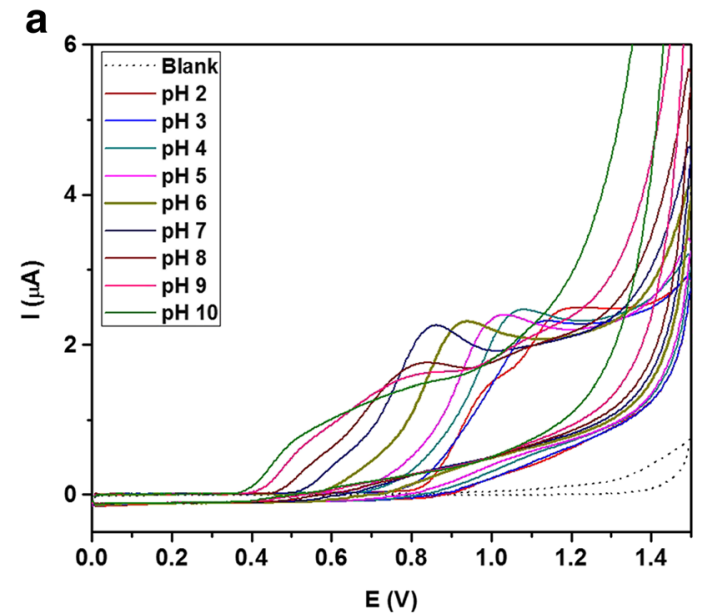

Fig. 2 Cyclic voltammograms (a) and peak current (-) and potential buffer solution; method, $\mathrm{CV}$ with a scan rate of $0.1 \mathrm{~V} / \mathrm{s}$

\section{Sample Analysis}

Apple root sample with content of Phl 95\% (commercial organic extract) has been purchased from Badmonkey Botanicals (Badmonkey Botanicals n.d.). The sample was dissolved in methanol/water $(50 / 50, v / v)$ and directly analyzed by adding a known amount to the supporting electrolyte. Results were calculated from the calibration curve. Determination of $\mathrm{Phl}$ in urine sample, based on the previously reported literature (Zhang and Zhang 2011), is important due to the possibility of extraction from the body through the urine. Different concentrations of $\mathrm{Phl}$ were found in urine and due to that urine samples were considered as suitable for investigation of matrix effect. Urine samples were diluted with supporting electrolyte in a ratio 1:10 and then analyzed. For recovery studies, standard addition method was used and the urine samples were spiked with aliquots of stock solution of Phl.

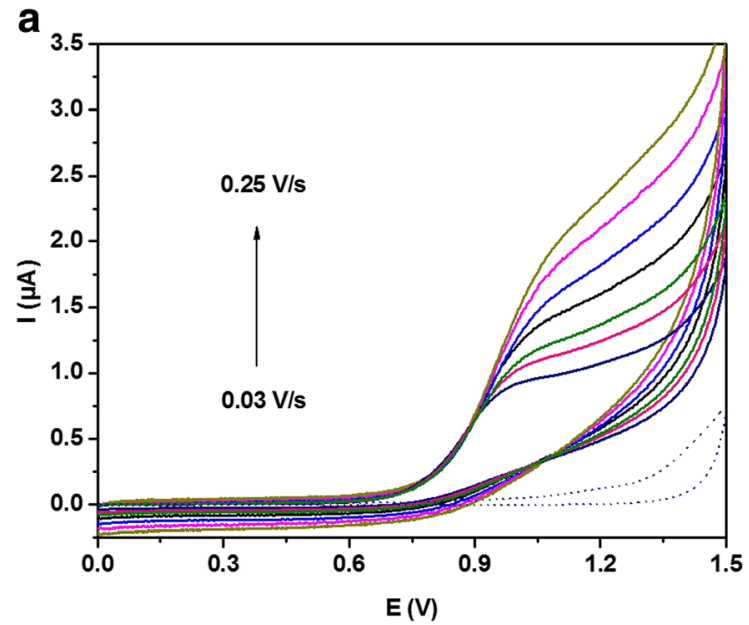

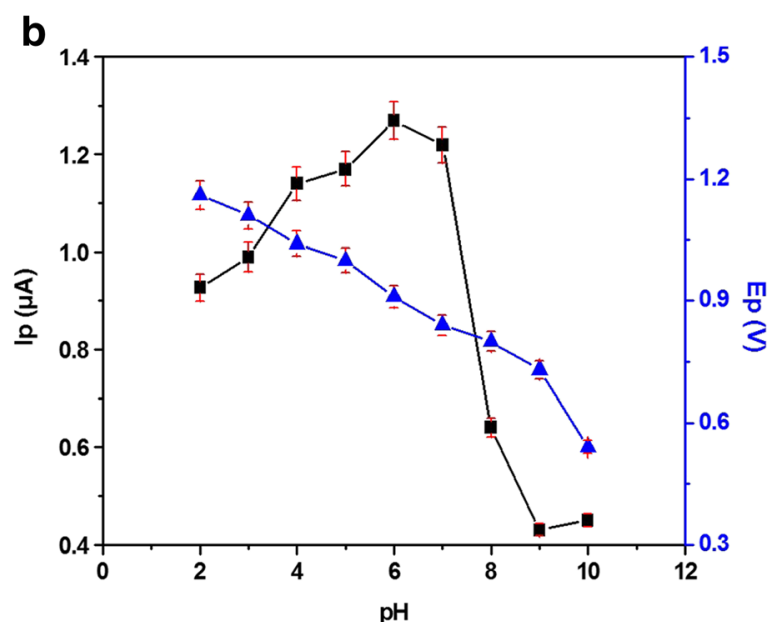

(b) in dependence of $\mathrm{pH}$; analyte, $0.1 \mathrm{mM} \mathrm{Phl}$; supporting electrolyte, $\mathrm{BR}$

\section{Results and Discussion}

\section{Electrochemical Behavior of Phlorizin at a BDD Electrode}

Cyclic voltammetry was employed to study the electrochemical behavior of $\mathrm{Phl}$. A typical voltammogram is shown in Fig. 1.

Phl exhibits a very well-defined oxidation peak with a peak potential around $+0.9 \mathrm{~V}$ in the anodic scan. In the reverse scan, no cathodic peak was observed indicating that the oxidation of the $\mathrm{Phl}$ is electrochemically irreversible.

\section{Effect of pH}

The effect of the $\mathrm{pH}$ value of the supporting electrolyte solution was investigated in the range from 2.0 to 10.0 using cyclic voltammetry. Figure $2 \mathrm{a}$ shows the corresponding response

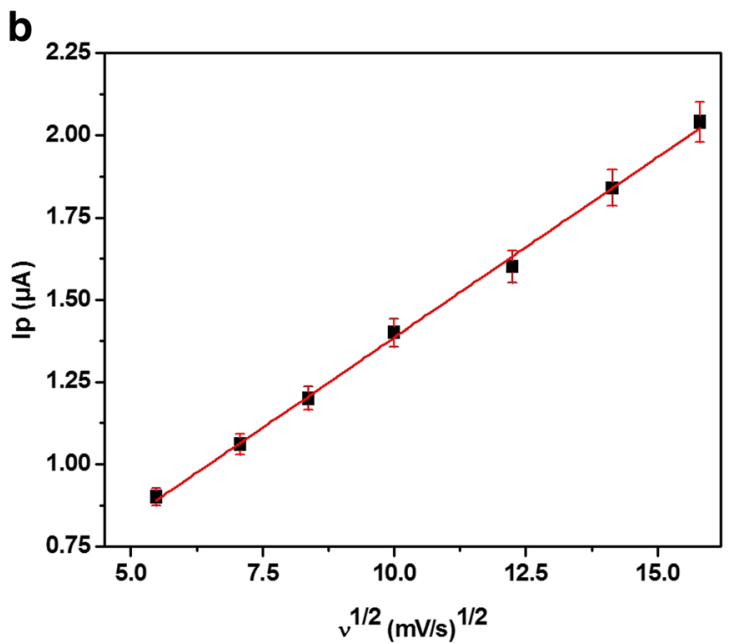

Fig. 3 Dependence of the peak current of Phl of cyclic voltammograms (a) on the square root of the scan rate (b); analyte, $0.1 \mathrm{mM}$ Phl; supporting electrolyte, BR buffer solution ( $\mathrm{pH}$ 6.0) 

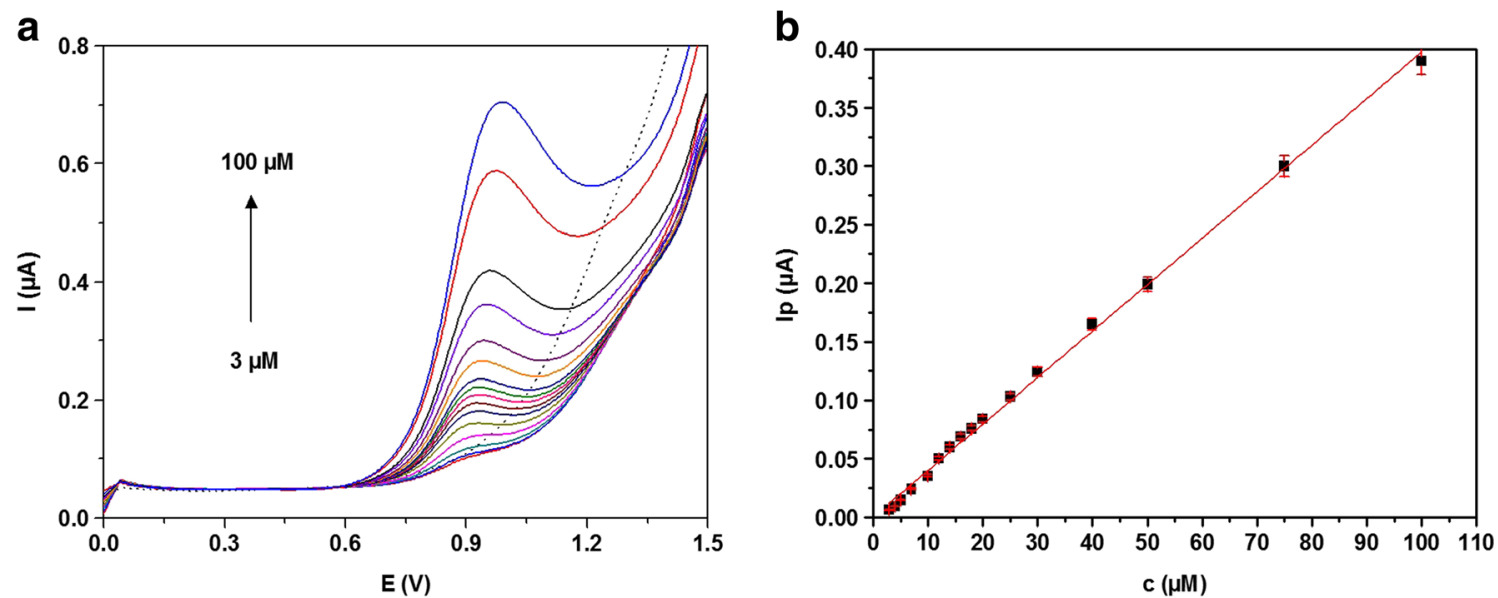

Fig. $4 \mathrm{SW}$ voltammograms for different concentrations of $\mathrm{Phl}$ (a) and calibration plot (b); analyte, Phl from 3 to $100 \mu \mathrm{M}$; supporting electrolyte, BR buffer solution (pH 6.0); parameters, scan rate $0.05 \mathrm{~V} / \mathrm{s}$, amplitude $0.01 \mathrm{~V}$; frequency of $20 \mathrm{~Hz}$

curves, Fig. $2 \mathrm{~b}$ the dependencies of the peak current and the potential on the $\mathrm{pH}$. Up to $\mathrm{pH} 6.0$, the signal increased whereas it became smaller at higher $\mathrm{pH}$. The peak potential of $\mathrm{Phl}$ was shifted to more negative values with increasing $\mathrm{pH}$. At pH 6.0 the peak current was highest; therefore this value was chosen for further experiments.

When varying the $\mathrm{pH}$ from 2.0 to 9.0 , the peak potential shifts to the more negative values according to the equation $E(V)=-0.063 \times \mathrm{pH}+1.293$. The slope of $63 \mathrm{mV}$ per $\mathrm{pH}$ unit is close to the ideal value of $59 \mathrm{mV}$ which indicates an equal number of protons and electrons in the electrochemical reaction. This behavior is in accordance with structurally similar phenolic antioxidants, where an equal number of protons and electrons is included in the electrochemical reaction. The probable mechanism of the oxidation might involve the formation of a radical or the introduction of a further $\mathrm{OH}$ group in the ortho-position of an existing phenol group with follow-up reactions such as dimerization or ensuing oxidation to the corresponding quinone.

\section{Effect of Scan Rate}

The effect of the scan rate in CV on the peak current of Phl was investigated (Fig. 3). The peak current depends linearly on the

Table 1 Results ${ }^{\mathrm{a}}$ obtained for the quantification of phlorizin in apple root sample

\begin{tabular}{ccc} 
Apple root sample & & \\
\hline Expected $(\mu \mathrm{M})$ & Found $(\mu \mathrm{M})$ & Recovery $(\%)$ \\
17.00 & $17.50 \pm 0.15$ & 103 \\
30.00 & $30.26 \pm 0.27$ & 101 \\
50.00 & $50.61 \pm 0.46$ & 101 \\
\hline
\end{tabular}

${ }^{\text {a }} n=3$ square root of the scan rate, indicating that the electrochemical reaction is controlled by diffusion (Fig. 3b). The corresponding equation, $\operatorname{Ip}(\mu \mathrm{A})=0.10975 \times v^{1 / 2}(\mathrm{mV} / \mathrm{s})+0.28782$, describes the linear regression yielding a coefficient $R^{2}=0.9980$.

\section{Analytical Performance of the Sensor}

SWV was selected as the electroanalytical technique for the quantitative determination of Phl. An amplitude of $0.01 \mathrm{~V}$, a scan rate of $0.05 \mathrm{~V} / \mathrm{s}$, and a frequency of $20 \mathrm{~Hz}$ provided the best results. Calibration curves were constructed correspondingly; Fig. 4a. The linear dependence of the current and concentrations of $\mathrm{Phl}$ are presented in Fig. 4b. The obtained currents were linear with concentration in the range from 3 to $100 \mu \mathrm{M}$ with a corresponding linear equation: $I(\mu \mathrm{A})=0.03973 \times c$ $(\mu \mathrm{M})+0.00278 ;\left(R^{2}=0.9978\right)$. The detection limit $\left(3 \sigma_{\mathrm{c}=10 \mu \mathrm{M}} / \mathrm{slope}\right)$ was calculated to be $0.23 \mu \mathrm{M}$. The repeatability ( $n=7$ measurements, $c=10 \mu \mathrm{M}$ Phl) were calculated as $\pm 0.9 \%$. It can be concluded that the proposed method offers quite excellent characteristics for the quantification of Phl.

Table 2 Results ${ }^{\mathrm{a}}$ obtained for the quantification of Phlorizin in urine samples

\begin{tabular}{ccc}
\hline Urine samples & & \\
\hline Expected $(\mu \mathrm{M})$ & Found $(\mu \mathrm{M})$ & Recovery $(\%)$ \\
0.00 & 0.00 & - \\
20.00 & $20.00 \pm 0.18$ & 100 \\
25.00 & $23.50 \pm 0.19$ & 94 \\
30.00 & $31.04 \pm 0.28$ & 103 \\
\hline
\end{tabular}

${ }^{\mathrm{a}} n=3$ 


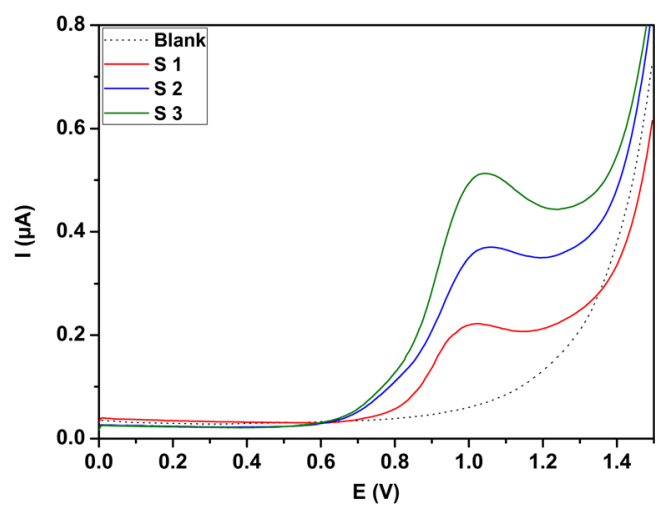

Fig. $5 \mathrm{SW}$ voltammograms of $\mathrm{Phl}$ standard solution and from apple root sample at same concentration level 17,30 , and $50 \mu \mathrm{M}$ each; supporting electrolyte, BR buffer ( $\mathrm{pH}$ 6.0); parameters, scan rate $0.05 \mathrm{~V} / \mathrm{s}$; amplitude $0.01 \mathrm{~V}$; frequency $20 \mathrm{~Hz}$

\section{Interference Studies}

The selectivity of the method toward $\mathrm{Phl}$ was investigated with potentially interfering compounds, such as caffeic acid (CaA), gallic acid (GA), catechol (CA), hydroquinone (HQ), phloretin (Phlt), ascorbic acid (AA), uric acid (UA), dopamine (DA), fructose (Fru), maltose (Mal), and glucose (Glu) at the same concentration level as the analyte $(30 \mu \mathrm{M})$. The results are given in the supplementary material (Fig. S1). As expected, structurally similar compounds (phenolic antioxidants: CaA, GA, CA, HQ, and Phlt) interfere by overlapping and increasing the response of Phl. Thus, in the presence of these compounds, $\mathrm{Phl}$ can be detected only as a sum of antioxidants. However, the carbohydrates under investigation, i.e., Mal, Fru, and Glu are not electrochemically active under the chosen experimental conditions. AA and DA do not interfere with $\mathrm{Phl}$ due to their lower oxidation potential under proposed experimental conditions. On the other hand, UA interferes by slightly decreasing of oxidation current of $\mathrm{Phl}$ and overlapping the peaks obtained for UA and Phl.

\section{Analytical Application of the Sensor}

The sensor was applied for the determination of Phl in a commercial apple root extract (Table 1) and in urine samples (Table 2). Concentrations of the analyte in the samples (S1, S2, and S3) were evaluated, and results are estimated from calibration curve. The corresponding voltammograms are shown in Fig. 5. All samples were analyzed in triplicate, and results are given as mean value from three measurements. From the data listed below, it can be concluded that the BDD electrode in combination with square wave voltammetry shows good recovery rates with negligible matrix effects for both apple root and urine samples. In the absence of other phenolic antioxidants, it can be successfully applied as replacement for the expensive and time-consuming separation methods.

\section{Conclusions}

The electrochemical determination of Phl was described using a boron-doped diamond electrode in combination with square wave voltammetry. The obtained results showed that proposed method toward the detection of phlorizin has a good repeatability and a satisfactory detection limit allowing quick determinations of Phl.

Acknowledgments Open access funding provided by University of Graz. EM wishes to acknowledgement Higher KOS Stipendien, financed by ADA and MEST and Austrian Agency for International Cooperation in Education and Research (OeAD-GmbH), Centre for International Cooperation \& Mobility (ICM). DMS wishes to acknowledgement Ministry of Education, Science and Technology, Republic of Serbia, project No 172030 and Magbiovin project (FP7-ERAChairs-Pilot Call-2013, Grant agreement: 621375).

\section{Compliance with Ethical Standards}

Conflict of Interest Eda Mehmeti declares that she has no conflict of interest. Dalibor M. Stanković declares that he has no conflict of interest. Astrid Ortner declares that she has no conflict of interest. Janez Zavašnik declares that he has no conflict of interest. Kurt Kalcher declares that he has no conflict of interest.

Ethical Approval This article does not contain any studies with human participants or animals performed by any of the authors.

Informed Consent Informed consent is not applicable in this study.

Open Access This article is distributed under the terms of the Creative Commons Attribution 4.0 International License (http:// creativecommons.org/licenses/by/4.0/), which permits unrestricted use, distribution, and reproduction in any medium, provided you give appropriate credit to the original author(s) and the source, provide a link to the Creative Commons license, and indicate if changes were made.

\section{References}

https://www.badmonkeybotanicals.com/

Chang W-T, Huang W-C, Liou C-J (2012) Evaluation of the antiinflammatory effects of phloretin and phlorizin in lipopolysaccharide-stimulated mouse macrophages. Food Chem 134(2):972-979. doi:10.1016/j.foodchem.2012.03.002

Crespy V, Aprikian O, Morand C, Besson C, Manach C, Demigné C, Rémésy C (2001) Bioavailability of phloretin and phloridzin in rats. J Nutr 131(12):3227-3230

de Koninck L (1835a) Ueber das Phloridzin (Phlorrhizin). Ann Pharm 15(1):75-77. doi:10.1002/jlac.18350150105

de Koninck L (1835b) Weitere Notiz über das Phloridzin. Ann Pharm 15(3):258-263. doi:10.1002/jlac.18350150307

Ehrenkranz JRL, Lewis NG, Ronald Kahn C, Roth J (2005) Phlorizin: a review. Diabetes Metab Res Rev 21(1):31-38. doi:10.1002/dmrr. 532

Gao F, Zheng D, Tanaka H, Zhan F, Yuan X, Gao F, Wang Q (2015) An electrochemical sensor for gallic acid based on $\mathrm{Fe}_{2} \mathrm{O}_{3}$ /electro-reduced graphene oxide composite: estimation for the antioxidant capacity index of wines. Mater Sci Eng C Mater Biol Appl 57:279287. doi:10.1016/j.msec.2015.07.025 
Kim MS, Park S-H, Han S-Y, Kim Y-H, Lee E-J, Yoon Park JH, Kang YH (2014) Phloretin suppresses thrombin-mediated leukocyteplatelet-endothelial interactions. Mol Nutr Food Res 58(4):698708. doi: $10.1002 / \mathrm{mnfr} .201300267$

Lee J-H, Regmi SC, Kim J-A, Cho MH, Yun H, Lee C-S, Lee J (2011) Apple flavonoid phloretin inhibits Escherichia coli O157:H7 biofilm formation and ameliorates colon inflammation in rats. Infect Immun 79(12):4819-4827. doi:10.1128/IAI.05580-11

Lijia X, Guo J, Chen Q, Baoping J, Zhang W (2014) Quantitation of phlorizin and phloretin using an ultra high performance liquid chromatography-electrospray ionization tandem mass spectrometric method. J Chromatogr B 960:67-72. doi:10.1016/j.jchromb.2014. 04.007

Lommen A, Godejohann M, Venema DP, Hollman PCH, Spraul M (2000) Application of directly coupled HPLC-NMR-MS to the identification and confirmation of quercetin glycosides and phloretin glycosides in apple peel. Anal Chem 72(8):1793-1797. doi:10. $1021 /$ ac 9912303

Ostroumova OS, Efimova SS, Schagina LV (2013) Phloretin-induced reduction in dipole potential of sterol-containing bilayers. J Membr Biol 246(12):985-991. doi:10.1007/s00232-013-9603-2

Pecková K, Musilová J, Barek J (2009) Boron-doped diamond film electrodes - new tool for voltammetric determination of organic substances. Crit Rev Anal Chem 39(3):148-172. doi:10.1080/ 10408340903011812

Pekec B, Feketefoldi B, Ribitsch V, Ortner A, Kalcher K (2013) Development of an electrochemical sensor for the determination of the total antioxidant capacity in berries based on boron doped diamond. J Electrochem Sci Eng. doi:10.5599/jese.2012.0024

Petkovic BB, Stankovic D, Milcic M, Sovilj SP, Manojlovic D (2015) Dinuclear copper(II) octaazamacrocyclic complex in a PVC coated GCE and graphite as a voltammetric sensor for determination of gallic acid and antioxidant capacity of wine samples. Talanta 132: 513-519. doi:10.1016/j.talanta.2014.09.025

Rebelo MJ, Rego R, Ferreira M, Oliveira MC (2013) Comparative study of the antioxidant capacity and polyphenol content of douro wines by chemical and electrochemical methods. Food Chem 141(1):566573. doi:10.1016/j.foodchem.2013.02.120

Schachl K, Alemu H, Kalcher K, Jezkova J, Svancara I, Vytras K (1997) Amperometric determination of hydrogen peroxide with a manganese dioxide-modified carbon paste electrode using flow injection analysis. Analyst 122(9):985-989. doi:10.1039/A701723E

Shin J-W, Kundu JK, Surh Y-J (2011) Phloretin inhibits phorbol esterinduced tumor promotion and expression of cyclooxygenase- 2 in mouse skin: extracellular signal-regulated kinase and nuclear factor- $\mathrm{kB}$ as potential targets. J Med Food 15(3):253-257. doi:10. 1089/jmf.2011.1851

Stanković DM (2015) Sensitive voltammetric determination of thymol in essential oil of Carum copticum seeds using boron-doped diamond electrode. Anal Biochem 486:1-4. doi:10.1016/j.ab.2015.06.026

Stanković DM, Kalcher K (2015) The immunosuppressive drugrapamycin-electroanalytical sensing using boron-doped diamond electrode. Electrochim Acta 168:76-81. doi:10.1016/j.electacta. 2015.03.200

Svorc L, Stankovic DM, Mehmeti E, Kalcher K (2014) Sensitive electrochemical determination of yohimbine in primary bark of natural aphrodisiacs using boron-doped diamond electrode. Anal Methods 6(13):4853-4859. doi:10.1039/C4AY00704B

Tirawattanakoson R, Rattanarat P, Ngamrojanavanich N, Rodthongkum N, Chailapakul O (2016) Free radical scavenger screening of total antioxidant capacity in herb and beverage using graphene/PEDOT: PSS-modified electrochemical sensor. J Electroanal Chem 767:6875. doi:10.1016/j.jelechem.2015.11.037

Tsao R, Yang R, Young JC, Zhu H (2003) Polyphenolic profiles in eight apple cultivars using high-performance liquid chromatography (HPLC). J Agric Food Chem 51(21):6347-6353. doi:10.1021/ jf0346298

Wang X, Zhang S, Liu Y, Spichtig D, Kapoor S, Koepsell H, Mohebbi N, Segerer S, Serra AL, Rodriguez D, Devuyst O, Mei C, Wüthrich RP (2013) Targeting of sodium-glucose cotransporters with phlorizin inhibits polycystic kidney disease progression in Han:SPRD rats. Kidney Int 84(5):962-968. doi:10.1038/ki.2013.199

Zhang X, Zhang Z (2011) Sweeping under controlled electroosmotic flow and micellar electrokinetic chromatography for on-line concentration and determination of trace phlorizin and quercitrin in urine samples. J Pharm Biomed Anal 56(2):330-335. doi:10.1016/j. jpba.2011.05.016

Zhu S-P, Liu G, Wu X-T, Chen F-X, Liu J-Q, Zhou Z-H, Zhang J-F, Fei S$J$ (2013) The effect of phloretin on human $\gamma \delta$ T cells killing colon cancer SW-1116 cells. Int Immunopharmacol 15(1):6-14. doi:10. 1016/j.intimp.2012.11.001 